\title{
Colloidal Electrolytes
}

$\mathrm{T}$ HE general discussion on colloidal electrolytes, organised by the Colloid Committee of the Faraday Society, took place at University College, London, on September 27-29. The meeting was well attended and a number of eminent foreign chemists were present as guests. This was the first general discussion organised by the Society that has ever been held at a London college. University College may for two special reasons be regarded as a happy choice of meeting place since in the first place Prof. F. G. Donnan (in the absence of the president of the Society) was chairman, and in the second place Thomas Graham carried out much of his pioneer work there. A more mundane reason for congratulating the Society on its arrangements was the success which attended them. The close proximity of lecture room, rest room and an excellent refectory reduced physical fatigue to a minimum and allowed the protagonists to expend all their energy in coping with intellectual problems.

The programme of the discussions was divided into Part I, General, (a) Theory, (b) Methods and Experimental Technique, and Part II, Special and Technical, (a) Soaps and other Long-Chain Colloidal Electrolytes, (b) Dyestuffs, (c) Silicates and Silicic Acid, $(d)$ Proteins, $(e)$ Other Substances. Prof. H. Freundlich (London) opened the meeting with a general introduction on the nature of colloidal electrolytes and their importance for colloid science. He pointed out that colloidal electrolytes can to-day be prepared in many cases as pure substances. As a class they are characterised by the fact that they form ions of colloidal size spontaneously. They can be classified into three types, those with ionic micelles sensible to dilution forming small dialysable ions; those with ionic micelles sensible to dilution but forming non-dialysable ions; and those not influenced by dilution. In the case of the proteins, their amphoteric nature gives them certain special properties.

The discussion on general theory, which followed, illustrated once again how mankind can be divided into two classes - those who think in terms of three dimensions and those who think in terms of mathematical abstractions. The former, among whom Prof. H. R. Kruyt (Utrecht) and Prof. A. J. Rabinovich (Moscow) may be mentioned, warned the meeting against being over-impulsive in extending to systems containing large ions of colloidal dimensions general equations such as those of the DebyeHückel theory, which had been worked out for systems containing only the small ions of the ordinary dialysable electrolyte. Nothing daunted, however, Prof. Donnan (London), with the support of Dr. G. S. Hartley (London), Dr. C. Robinson (London) and others, by adding new factors to their equations and extending in this way their range of operations, organised a charge of mathematicians on to the field and engaged in what looked like a winning battle. Extrapolation from molecular dimensions to colloidal dimensions is, after all, no more dangerous than extrapolation from extended surfaces to colloidal dimensions.

An excursion from the main battle turned up in a lively discussion as to whether a charged colloidal particle were more profitably regarded as a large colloidal ion surrounded by small gegenions or as a large colloidal particle surrounded by an electrical double layer. Prof. E. K. Rideal (Cambridge) dealt with the problem in the detached manner of a judge, but unlike most judges produced experimental evidence in support of his opinions. Prof. Kruyt (Utrecht) pointed out with considerable effect that paraffin and water make an electrical double layer without the intervention of any ions, and suggested that the influence of oriented dipoles should be considered. This was immediately responded to by Dr. N. K. Adam (London), who stated that the $\varepsilon$-potential could be built up by dipoles but the $\zeta$-potential could not. It is interesting to note that, on a later occasion, Mrs. Laing-McBain described the $\zeta$-potential as "rather mythical"-to the consternation of some but the comfort of others.

The meeting was brought back to earth or, in other words, to the realm of experimental science, by the papers of Prof. A. Frumkin and Dr. Proskurnin (Moscow), Mr. G. S. Adair and Mrs. Adair (Cambridge) and Dr. H. B. Oakley (London) on new developments in experimental methods.

In the special sections, the discussion on the soaps turned rather round the criticism made by Mrs. Laing-McBain that the electro-kinetic theory of soap solutions had unfortunately grown up apart from the electrolytic theory of ions; the two theories, however, could be brought together. The properties of soap curds and solid soaps and the mechanism of the sudden change which a critical temperature provokes in a soap solution received attention. While some speakers attributed this to a change in the properties of the solution, others favoured a change in the properties of the solid soap. Dr. Adam (London) showed that ionic effects and an influence on the cohesion of the long hydrocarbon chains are both involved.

The discussion on dyestuffs was the most animated of the whole meeting, and the interest betrayed is a measure of the great progress which has been made in recent years in the colloidal chemistry of these substances. Prof. E. Elöd (Karlsrühe) started the ball rolling by a paper discussing the reaction between protein fibres and substantive dyestuffs and Messrs. Valkó (Ludwigshafen), Robinson (London), Moreton (Braintree) and Hartley (London) ranged the discussion round the problem of the size and state of aggregation of the dye particle, the influence of dissolved salts on this and on the factor intro. duced by the size of pore in the material being penetrated by the dye. In the complete absence of salts, dyeing does not occur, and this was generally attributed to the aggregated state of the dye particles preventing diffusion, though an alternative suggestion that the salt influences the properties of the ultrafilter was also put forward.

A short discussion on silica was launched by Prof. Rabinovich (Moscow) and Prof. W. D. Treadwell (Zurich). The latter described the complicated changes occurring in silica gels on standing due to the polymerisation of the silica molecules.

The discussion on the proteins was opened by Dr. D. Jordan Lloyd (London) who indicated that the properties of this class of colloidal electrolytes are influenced by three special features, the static nature of the ionic equilibrium where zwitterions are concerned, the special capacity of the hydrogen ion to influence this equilibrium on account of its power of forming co-ordinated links with both acid and basic 
groups, and the power of large multivalent gegenions to form compounds of greater stability with proteins than small mono- or di-valent gegenions. To these Prof. Rideal (Cambridge) added a fourth in the power of proteins to form co-ordination complexes with dipole molecules of the type of thiourea. The discussion centred largely on titration curves, and Dr. R. K. Schofield (Harpenden) brought forward a valuable new technique based on the use of metaphosphoric acid. Prof. E. J. Bigwood (Brussels) dealt with diffusion in gelatin gels and came in for some friendly criticism at the hands of $\mathrm{Mr}$. E. Hatschek (London). Dr. E. B. R. Prideaux (Nottingham) dealt with diffusion potentials of protein ions and Prof. T. Weigert (Leipzig) with colloidal electrolytes in photographic emulsions. Prof. E. Hammarsten
(Stockholm) and his colleagues pursued the chemistry of the proteins into the chromosomes-to the satisfaction of Dr. Dorothy Wrinch (Oxford), who has worked out the electric behaviour of these bodies. Two papers by Prof. K. Linderstrøm-Lang (Copenhagen), in the absence of the author, were taken as read and the same fate unfortunately fell to the contributions on colloidal carbohydrates from Profs. A. Lottermoser (Dresden) and M. Sameč (Ljubljana). The meeting was brought to an end by a paper on tungsten sols contributed by Dr. F. Eirich (Vienna).

A brief notice cannot do justice to the thirty-seven official papers given at the meeting or to the ensuing discussions, but the full printed report will be issued by the Faraday Society on January 1, 1935.

D. J. L.

\section{Economic Problems of Technological Progress}

$\mathrm{I}^{\mathrm{N}}$ a contribution to the discussion on "The Need for a Technique of Economic Change" arranged by the Department of Industrial Co-operation of Section F (Economic Science and Statistics) at the Aberdeen meeting of the British Association, Mr. N. F. Hall examined the more specifically economic problems which arise as a consequence of technological improvements. Economics, like other sciences, he pointed out, has in the past made progress by adopting the well-tried method of limiting the number of variables in any problem under review. The necessity for the limitation of variables has resulted in the development of the idea of the 'Stationary State', which has been the most fruitful abstraction for purposes of economic analysis. As soon, however, as one or more of our hypothetical constants becomes a variable, the stimulus of a change in population or increasing technological knowledge alters our simple stationary State into a dynamic system.

The technique of economic change is therefore the accurate interpretation of changes in relative prices under dynamic conditions. Among such changes are those associated with developments in scientific know ledge, which make possible new methods of production and lead either to the output of entirely new goods or to the better fabrication of old ones, or to both things concurrently. This sort of technological change gives rise to numerous economic disturbances, such as the problem of obsolescence or the territorial regrouping of industries. Limiting the subject, however, for the present purpose to the economic difficulties which arise in securing the orderly development of the new processes rather than in the decent burial of the old, we are confronted with a special case of the general problem of 'uncertainty'. The economist has learned in the last decade to distinguish between those incidents in economic life which are called risks and those which he now defines as 'uncertainties'. A risk such as that of shipwreck or fire is a recurrent circumstance and consequently capable of quantitative measurement and actuarial treatment. Uncertainties, however, are unpredictable and incapable of quantitative measurement; they arise out of the freedom of the mind and the continual possibility of change in human tastes and human knowledge. They reflect in brief the difference between the hypothetical stationary State of simpler economic theory and the real world.

The necessity for specialisation introduces the element of 'true' uncertainty and a specialised economy can only be, in a very limited sense, a competitive one. The greater the degree of specialisation, the larger will be the zone of uncertainty, as the obstacles in the way of adjustment and re-adjustment will increase as specialisation continues. Here then is the economic problem which is created by every forward step in scientific and in technological knowledge. The utilisation of advancing knowledge in the service of society demands an ever-increasing specialisation both of the men and of the capital goods with which they co-operate. The more both plant and labour are specialised, the greater the difficulties of bringing about further changes, particularly when these changes are on so large a scale that they require a more extensive re-distribution of both men and plant than can be secured by a wise direction of new entrants into industry or by far-seeing investment of new savings. The need for a technique of economic change arises because the benefit of further developments in scientific knowledge would be lost unless in the economic sphere the rigidity which specialisation necessarily brings with it can be overcome.

In the past, neglect of the price problems set up by uncertainty in connexion with the task of introducing new plant and new processes has been a cause of many difficulties. The inherent tendency in free as in 'planned' economic systems to over-develop the new thing seems in large part to arise from a misunderstanding of the way in which these zones of uncertainty, arising out of technological change, influence the price system, so that the economic danger signals given by price changes are either disregarded or entirely ignored. Confusion arises because changes in the prices of, and the economic return upon, new fixed plant--which are the result of changes in the element of uncertainty-are mistakenly considered to represent a permanent shift in the nature of the demand for the particular plant and its products.

Nearly all proposals for monetary manipulation seem to be open to the fatal objection that they are built upon the assumption that there is little or no change in technological processes and that uncertainty is absent. The result is that they cannot be made to apply to 'real' conditions. Proposals for arbitrary alterations in the supply of legal tender money will also fail to achieve the objectives of stabilising the price level or of providing a quantity 